\title{
In vitro oocysticidal sporulation inhibition of Eimeria tenella and antioxidant efficacy of ethanolic and aqueous extracts of Conyza aegyptiaca
}

\author{
Emmanuel Tana Toah ${ }^{1 \star}$, Vincent Khan Payne ${ }^{1}$, Yamssi Cedric ${ }^{2}$, Noumedem Anangmo \\ Christelle Nadia ${ }^{3}$ and Atiokeng Tatang Rostand Joël ${ }^{1}$
}

\begin{abstract}
${ }^{1}$ Department of Animal Biology, Faculty of Science, University of Dschang, P.O. Box 067, Dschang, Cameroon. 2Department of Biomedical Sciences, Faculty of Health Sciences, University of Bamenda, P.O. Box 39 Bambili, Cameroon. ${ }^{3}$ Department of Microbiology, Hematology and Immunology, Faculty of Medicine and Pharmaceutical Sciences, University of Dschang, P.O. Box 96, Dschang, Cameroon.

*Corresponding author. Email: toahemmanuel8@gmail.com; Tel: +237 675718524/+237 666529534.
\end{abstract}

Copyright @ 2021 Toah et al. This article remains permanently open access under the terms of the Creative Commons Attribution License 4.0, which permits unrestricted use, distribution, and reproduction in any medium, provided the original work is properly cited.

Received 16th January, 2021; Accepted 1st February, 2021

\begin{abstract}
Avian coccidiosis is probably one of the most expensive parasitic diseases with major economic impact on poultry industries worldwide. The purpose of this study was to evaluate the ethanolic and aqueous extracts of Conyza aegyptiaca in terms of phytonutrients, in vitro oocysts sporulation inhibition and antioxidant properties. The extraction process of plant leaf powder $(100 \mathrm{~g})$ pulverized using a clean manual grinder was carried out in ethanol and hot water and the yields were calculated as a percentage ratio of extract mass on plant powder mass after solvent evaporation. Phytochemical analysis procedures were performed to determine the presence of phytonutrients. The in vitro oocysticidal sporulation inhibition was determined at five different concentrations $(0.25 ; 0.5 ; 1 ; 2$ and $4 \mathrm{mg} / \mathrm{ml})$ of each extract in petri dishes each containing 3000 unsporulated oocysts and examined after 24 and 48 hours under a microscope. In vitro antioxidant capacity of extracts was estimated using different assays. Quantitative aqueous extract (11.72\%) was higher than ethanolic extract $(4.34 \%)$. In terms of qualitative yields, ethanolic extract revealed higher phytonutrients investigated $(100 \%)$ than aqueous extract $(42.86 \%)$. The sporulation inhibition of ethanolic extract was generally higher than the aqueous extract after 24 and $48 \mathrm{~h}$ and varied according to the different tested concentrations. In all the antioxidant assays, ethanolic extract exhibited significant free radical scavenging activity with inhibitory concentration $\left(\mathrm{IC}_{50}=26.10 \pm 1.09\right)$ close to that of ascorbic acid at the probability level of $5 \%$ error $(p<0.05)$. The ethanolic extract with higher free radical scavenging activities and ferric reducing effect also showed significant higher content of both phenols $(127.01 \pm 3.99 \mathrm{mgGAE} / \mathrm{g})$ and flavonoids $(108.66 \pm 3.49 \mathrm{mgCE} / \mathrm{g})$ than aqueous extracts, suggesting correlation between phenolic content and antioxidant activity. Data from this study could be used for developing bioactive elements for natural anticoccidials and antioxidants of health promoting activities.
\end{abstract}

Keywords: Anticoccidial, antioxidant, Cameroon, Conyza aegyptiaca, Eimeria tenella.

\section{INTRODUCTION}

Coccidiosis is one of the most common chicken diseases caused by protozoan parasites of the genus Eimeria which can seriously affect the health and productivity of livestock (Adnane et al., 2013; El-Ashram et al., 2019). Worldwide, coccidiosis constitutes a major parasitic disease in poultry and other domestic animals (Sundar et al., 2017). Birds ingest sporulated oocysts orally and the infection can lead to clinical coccidiosis primarily in young birds, whereas adults are mostly healthy carriers (Castañeda and González, 2015). Seven distinct Eimeria species have been 
identified in chickens (Gallus gallus domesticus), with six species colonizing the intestinal tract (intestinal coccidiosis) and one species (Eimeria tenella) infecting the ceca (cecal coccidiosis) (Frölich et al., 2013; Fatoba and Adeleke, 2018). According to their pathogenicity, species responsible for chicken coccidiosis can be classified into three types: Slightly pathogenic (Eimeria mitis and Eimeria praecox), pathogenic (Eimeria acervulina, Eimeria maxima and Eimeria brunetti) and highly pathogenic (Eimeria necatrix and Eimeria tenella) (Hady and Zaki, 2012; Fatoba and Adeleke, 2018). Eimeria tenella is most responsible for severe coccidiosis and increased mortality in domestic chickens (Kant et al., 2013). Most of these Eimeria species affect chicken production as a result of poor feed conversion, reduced growth rate and increased mortality impacting a huge economic loss to poultry industry (AlGawad et al., 2012). According to Abdul and Muhammed (2016), coccidiosis may cost the United States commercial chicken industry about $\$ 90$ million annually and about $\$ 2.4$ billion in the layer and broiler industries worldwide. Thus, coccidiosis is probably the most expensive and wide spread infectious disease in commercial chicken systems.

Since the discovery of sulphonamides as a cure for coccidiosis in chickens, many ionophorous and chemical anticoccidial feed additives have been used. Unfortunately, with the widespread and uncontrolled use of these anticoccidial drugs (Amprolium, Robenidine, Sulphaquinoxaline, and Monensin), the main problem associated with their poor response is development of resistance in Eimeria species (Firouzi et al., 2014). In the external environment, farmers usually fight against this disease by applying disinfectant compounds. Commonly used disinfectants include some phenolic products such as ammonia, methyl bromide and carbon disulfide (Abbas et al., 2015). Parasite resistance and side effects of some anticoccidial drugs have serious consequences on disease control. Toxic effects of these products represent a danger to the users and health of animals and therefore their use has been restricted (Yamssi et al., 2017). The increased occurrence of resistance against all anticoccidial drugs has left the poultry industry with renewed challenge for coccidiosis prevention and control and has propelled the search for other strategies (Firouzi et al., 2014). With the currently increasing problems of drug-resistance and pressure from consumers to ban chemical drugs from animal feeds, phytobiotics (plant based materials) are now mostly considered as alternatives over chemicals for coccidian control in poultry farming (Adulugba et al., 2017).

Previous findings have reported that active free radicals with very short half-life and high reactivity are by-products of normal metabolism which induce oxidative damage to biomacromolecules, including DNA, proteins, membrane lipids and carbohydrates when there is an imbalance between free radical production and antioxidant defense systems (Shivani and Anjali, 2018). The systemic quantity of free radicals is higher than normal in disease states including coccidiosis and is known to be produced during the host's cellular immune response to invasion by parasite species (Arulselvan et al., 2016). Free radicals may be either Oxygen derived or Nitrogen derived. The most common reactive oxygen species (ROS) include superoxide anion $\left(\mathrm{O}_{2}\right)$, hydrogen peroxide $\left(\mathrm{H}_{2} \mathrm{O}_{2}\right)$, peroxyl radicals (ROO) and reactive hydroxyl radicals $(\mathrm{OH})$ (Shivani and Anjali, 2018). The nitrogen derived free radicals are nitric oxide (NO), peroxy nitrite anion (ONOO), Nitrogen dioxide $\left(\mathrm{NO}_{2}\right)$ and Dinitrogen trioxide $\left(\mathrm{N}_{2} \mathrm{O}_{3}\right)$. Antioxidants or inhibitors of oxidation are compounds which retard or prevent oxidation by their free radical scavenging activities and in general prolong the life of the oxidizable matter (Priya et al., 2017; Phuyal et al., 2020). In order to reduce the oxidative damage of active free radicals, many synthetic antioxidants such as butylated hydroxytoluene $(\mathrm{BHT})$ and butylated hydroxyanisole $(\mathrm{BHA})$ with a strong antioxidant capacity are widely used in food industry. However, frequent discovery of potential harmful effects of synthetic antioxidants on human health, such as liver damage and carcinogenesis has led to public interest in natural antioxidants as an alternative. Therefore, some natural and safe antioxidants, including ascorbate, tocopherols, flavonoids and phenolic compounds from plants and microorganisms, have been developed and used in food processing to improve body's antioxidant defenses and reduce oxidative stress due to parasite species infection (Zou et al., 2015). In fighting against coccidiosis, a drug with both anticoccidial effect and antioxidant activity can be more efficient. Therefore, to combat this disease, there is urgent need to identify new effective drugs that are safe for animals and the environment. The advantage of using plants is linked to the fact that they contain a large variety of compounds with a wide range of biological activities (Riyadh et al., 2014).

Conyza aegyptiaca (L.) Aiton belonging to the family Asteraceae is an annual or biennial aromatic herb mainly distributed in Africa, tropical Asia and Australia (Mahmoud et al., 2009; Kpegba et al., 2011). This plant is an erect multiple stem plant, branching extensively at the base, decreasing upwards and the stems can be up to $1 \mathrm{~m}$ in height with stiff hairs. According to Mahmoud et al. (2009), phytochemical studies of Conyza aegyptiaca have led to the isolation of diterpenes, triterpenes, sesquiterpenes, flavonoids and phloroglucinol glucoside derivative [2,4dihydroxy-6- ( $\beta$-D-glucopyranosyloxy) phenyl]-butan-1one, roseoside and kaempferol-3-O- $\beta$-D glucopyranoside in the areal parts of the plant and these phytochemicals possess antioxidant activity. The plant is used in folk medicine as an anthelmintic and a soothing for skin diseases. Previous pharmacological studies have shown that its polar extracts possess antiviral and antimicrobial activities. Akakpo et al. (2016) reported that $C$. aegyptiaca is widely used in West Africa to overcome malaria, sickle cell disease, sore throat, diabetes. In the Western Highlands of Cameroon, traditional healers have reported that the leaves of $C$. aegyptiaca are used to treat vomiting, dysentery, typhoid, protozoan diseases, gastrointestinal 
disorders and malaria. The potential benefits of this plant might be due to the presence of the various phytochemical elements and as a result, possess anticoccidial and antioxidant properties (Akakpo et al., 2016).

Ethnomedicinal practices could be recognized and encouraged as alternatives to chemical drugs and empower farmers to use the available resources for the prevention and control of livestock diseases. According to Abbas et al. (2015), a number of in vitro experiments have recently proven remarkable anticoccidial effects of different herbal extracts and essential oils on inhibition of sporulation of coccidian oocysts. The use of $\boldsymbol{C}$. aegyptiaca extracts as an anticoccidial substance has not yet been developed and no studies have been reported in this regard. This study was therefore designed to develop a scientific basis of $C$. aegyptiaca as an anticoccidial and antioxidant remedy prior to its adoption as a novel approach for parasite control.

\section{MATERIALS AND METHODS}

\section{Chemicals and reagents}

Reagents for the preparation of Hanks buffered salt solution (HBSS) and all other materials of analytical grade were obtained from the Animal Biology Laboratory, Faculty of Science, University of Dschang. $2.5 \%$ potassium dichromate $\left(\mathrm{K}_{2} \mathrm{Cr}_{2} \mathrm{O}_{7}\right)$ was used as a culture media and phenol for in vitro disinfectant.

\section{Plant collection and authentication}

Conyza aegyptiaca plant was primarily and locally identified due to its medicinal properties by indigenes of Mbessa Village in Belo Sub Division, Boyo division, North West Region of Cameroon. The plant was later harvested and taken to the Cameroon National Herbarium Yaounde, where a scientific classification was assigned by a Botanist using a voucher specimen registered under the reference No: 5604/SRFCam.

\section{Preparation of ethanolic and aqueous extracts}

The leaves of $C$. aegyptiaca were air-dried at room temperature under shade in the Laboratory of Biology and Applied Ecology. The dried leaves were pulverized using a manual grinder under strict hygienic conditions. One hundred grams of the plant powder were macerated in 1.5 $L$ ethanol. The mixture was stirred three times daily and 72 hours later, the resulting solution was filtered using a sieve and Whatman Paper $\mathrm{N}^{\circ} 2$. The filtrate was then distributed in three large plates and concentrated by evaporating the solvent at $50^{\circ} \mathrm{C}$ in an oven for three days. A similar procedure was used for the aqueous extract, except that $100 \mathrm{~g}$ of powder were poured into $1.5 \mathrm{~L}$ of hot distilled water. The mixture was stirred and allowed to cool for 4 hours. The resulting solution was filtered using a sieve and Whatman Paper $\mathrm{N}^{\circ}$ 2. The filtrate was concentrated by evaporating the solvent at $50^{\circ} \mathrm{C}$ in an oven for three days.

\section{Plant extract yields}

The yield was calculated for each extract using the following formula after solvent evaporation and stored in bottles at $4^{\circ} \mathrm{C}$ in the refrigerator till usage.

$$
\text { Yield }=\frac{\text { Mass of extract }}{\text { Mass of dried plant powder }} \times 100
$$

\section{Phytochemical analysis of plant extracts}

Extracts were tested for the presence of phenolic compounds, alkaloids, flavonoids, polyphenols, tannins, saponin, triterpenes and steroids as described by Builders et al. (2011) in the Laboratory of Microbiology and Antimicrobial Substances, University of Dschang.

\section{Preparation of test solutions}

A stock solution for the aqueous extract with a concentration of $8 \mathrm{mg} / \mathrm{ml}$ was prepared by weighing $80 \mathrm{mg}$ of dried extract using an electronic scale balance and dissolved in $1 \mathrm{ml}$ of distilled water in a mortar. When the extract was fully dissolved after thorough stirring, $9 \mathrm{ml}$ of distilled water was added and the homogenate transferred into a beaker. For the organic extracts, a stock solution was equally prepared and the same amount of extract was first mixed with $0.3 \%$ tween to facilitate dissolution of the organic extract with distilled water. Stock solutions with concentrations of $8 \mathrm{mg} / \mathrm{ml}$ were thus obtained and from these stock solutions, $4,2,1,0.5$ and $0.25 \mathrm{mg} / \mathrm{ml}$ concentrations were produced by serial dilution (dilution factor 2) for oocysticidal evaluation.

\section{Acquisition and propagation of coccidia parasites}

Eimeria tenella was provided by the Faculty of Veterinary Medicine, Department of Veterinary Parasitology and Entomology, Ahmadu Bello University Zaria, Nigeria. Four healthy three weeks old chicks were orally infected with Eimeria tenella sporulated oocysts. Seven days post infection, the chicks were slaughtered with competency registration for schedule 1 killing (Scientific Procedures) (ACT, 1986). The ceca were removed and contents plus the mucosal and deeper muscle layers carefully scraped and placed in a beaker containing HBSS and blended. Trypsin was added to $1.5 \%$ of the total volume (to break down any connective tissue) and incubated in a water bath at $41^{\circ} \mathrm{C}$ for one hour, while swirling the flask occasionally. The homogenate was strained through a double layer of muslin 
and centrifuged at $2000 \mathrm{rpm} / \sim 750 \mathrm{~g}$ for 12 minutes. The supernatant was poured off and replaced with HBSS pH 7.6 as a wash. The washes were repeated three times in HBSS and oocyst harvest was enumerated microscopically and diluted to a concentration of 3,000 oocysts $/ \mathrm{ml}$ for in vitro studies.

\section{In vitro sporulation inhibition of extracts}

Two millitres volume in $5 \mathrm{ml}$ Petri dishes comprising $1 \mathrm{ml}$ of the test solution of each concentration of the extracts $(0.25$, $0.5,1,2$ and $4 \mathrm{mg} / \mathrm{ml}$ ) and $1 \mathrm{ml}$ of the parasitic suspension of 3000 unsporulated oocysts were incubated at $28^{\circ} \mathrm{C}$. For comparison, phenol at $5 \%$ was used as a reference drug. The set up was examined after 24 hours and 48 hours under a light microscope using objective 40x and repeated three times for each treatment and control in the same conditions. The number of sporulated oocysts and nonsporulated oocysts were counted and the percentage of sporulation was estimated by counting the number of sporulated oocysts in a total of 100 oocysts. The sporulation inhibitory percentage was calculated as follows:

$$
(\mathrm{Sp}) \mathrm{IP}(\%)=\frac{\mathrm{Sp} \% \text { of control }-\mathrm{Sp} \% \text { of extract }}{\mathrm{Sp} \% \text { of control }} * 100
$$

Where: $(\mathrm{Sp}) \mathrm{IP}=$ Sporulation(sp) inhibition percentage

\section{In vitro antioxidant evaluation of extracts}

\section{Total phenol contents (TPC)}

The amount of total phenols was determined by the FolinCiocalteu reagent method. The reaction mixture consisted of $20 \mu \mathrm{L}$ of extract $(2000 \mu \mathrm{g} / \mathrm{mL}), 1380 \mu \mathrm{L}$ of distilled water, $200 \mu \mathrm{l}$ of 2 N FCR (Folin Ciocalteu Reagent) and $400 \mu \mathrm{L}$ of a $20 \%$ sodium carbonate solution. The mixture was incubated at $40^{\circ} \mathrm{C}$ for $20 \mathrm{~min}$. After cooling, the absorbance was measured at $760 \mathrm{~nm}$. In the control tube, the extract volume was replaced by distilled water. A standard curve was plotted using Gallic acid $(0-0.2 \mu \mathrm{g} / \mathrm{mL})$. The tests were performed in triplicate and the results were expressed as milligrams of Gallic Acid Equivalents (mgGAE) per gram of extract.

\section{Total flavonoid content (TFC)}

The amount of total flavonoids was determined by the Aluminum chloride method. Ethanolic solution of extracts $(100 \mu \mathrm{L}, 2000 \mu \mathrm{g} / \mathrm{ml})$ was mixed with $1.49 \mathrm{~mL}$ of distilled water and $30 \mu \mathrm{L}$ of a $5 \% \mathrm{NaNO}_{2}$ solution. After $5 \mathrm{~min}, 30$ $\mu \mathrm{L}$ of $10 \% \mathrm{AlCl}_{3} \mathrm{H}_{2} \mathrm{O}$ solution were added. After $6 \mathrm{~min}, 200$ $\mu \mathrm{l}$ of $0.1 \mathrm{M}$ sodium hydroxide and $240 \mu \mathrm{l}$ of distilled water were added. The solution was well mixed and the increase in absorbance was measured at $510 \mathrm{~nm}$ using a UV-Visible spectrophotometer. The total flavonoid content was calculated using standard catechin calibration curve and results expressed as milligrams of Catechin Equivalents (mgCE) per gram of extract

\section{Ferric reducing antioxidant power (FRAP) assay}

Ferric reducing power was determined by the $\mathrm{Fe}^{3+}-\mathrm{Fe}^{2+}$ transformation in the presence of the extracts. The $\mathrm{Fe}^{2+}$ was monitored by measuring the formation of Perl's Prussian blue at $700 \mathrm{~nm}$. Different volumes $(400,200,100$, $50,25 \mu \mathrm{L}$ ) of ethanolic extracts prepared at $2090 \mu \mathrm{g} / \mathrm{mL}$ were mixed with $500 \mu \mathrm{L}$ of phosphate buffer $(\mathrm{pH} 6.6)$ and $500 \mu \mathrm{L}$ of $1 \%$ potassium ferricyanide and incubated at $50^{\circ} \mathrm{C}$ for $20 \mathrm{~min}$. Then $500 \mu \mathrm{L}$ of $10 \%$ trichloroacetic acid were added to the mixture and centrifuged at $3000 \mathrm{rpm}$ for 10 min. The supernatant $(500 \mu \mathrm{L})$ was diluted with $500 \mu \mathrm{L}$ of water and mixed with $100 \mu \mathrm{L}$ of freshly prepared $0.1 \%$ ferric chloride. The absorbance was measured at $700 \mathrm{~nm}$. All the tests were performed in triplicate and the results were the average of three observations. Vitamin $\mathrm{C}$ was used as a positive control. Increased absorbance of the reaction mixture indicated a higher reduction capacity of the sample (Noghogne et al., 2015).

\section{Nitric oxide radical scavenging (NO) assay}

The method reported by Chanda and Dave (2009) was used with slight modification. To $0.75 \mathrm{~mL}$ of $10 \mathrm{mM}$ sodium nitroprusside in phosphate buffer was added $0.5 \mathrm{~mL}$ of extract or reference compounds (Vitamin $\mathrm{C}$ and Butylated hydroxytoluene (BHT)) in different concentrations (62.5 $1000 \mu \mathrm{g} / \mathrm{mL}$ ). The resulting solutions were then incubated at $25^{\circ} \mathrm{C}$ for $60 \mathrm{~min}$. A similar procedure was repeated with methanol as blank which served as negative control. To $1.25 \mathrm{~mL}$ of the incubated sample, $1.25 \mathrm{~mL}$ of Griess reagent ( $1 \%$ sulfanilamide in $5 \%$ phosphoric acid and $0.1 \%$ $\mathrm{N}$-1-napthylethylenediamine dihydrochloride in water) was added. A final concentration range of $12.5-200 \mu \mathrm{g} / \mathrm{mL}$ $(12.5,25,50,100$ and $200 \mu \mathrm{g} / \mathrm{mL})$ was obtained. After 5 min of incubation in the dark at room temperature, the absorbance of the chromophore formed was measured at $540 \mathrm{~nm}$. Percentage inhibition of the nitrite oxide generated was measured by comparing the absorbance values of control and test samples. The percentage of inhibition was calculated according to the following equation:

$\%$ inhibition $=\left(1-\left(A_{1} / A_{0}\right)\right) \times 100$

Where: $A_{l}=$ absorbance of the extract or standard and $A_{0}=$ absorbance of the negative control.

\section{2, 2-Diphenyl-1-picrylhydrazyl (DPPH) radical scavenging assay}

Pure ethanol was used to calibrate the counter. The extract $(2000 \mu \mathrm{g} / \mathrm{mL})$ was twofold serially diluted with ethanol and 
one hundred microliters of the diluted extract were mixed with $900 \mu \mathrm{L}$ of $0.3 \mathrm{mM}$ 2,2-diphenyl-1-picrylhydrazyl (DPPH) ethanol solution to give a final extract concentration range of $12.5-200 \mu \mathrm{g} / \mathrm{mL}(12.5,25,50,100$ and 200 $\mu \mathrm{g} / \mathrm{mL}$ ). After $30 \mathrm{~min}$ of incubation in the dark at room temperature, the optical densities were measured at 517 $\mathrm{nm}$. Ascorbic acid (Vitamin C) was used as control. Each assay was done in triplicate and the results recorded as the mean \pm standard deviation (SD) of the three findings were presented in tabular form. The radical scavenging activity (RSA, in \%) was calculated as follows:

$\mathrm{RSA}=\frac{\text { Absorbance of DPPH }- \text { Absorbance of sample }}{\text { Absorbance of DPPH }} \times 100$

Regression lines were plotted using the values of the different percentages of inhibition and the logarithmic decimal of the extract concentrations in order to determine the $\mathrm{IC}_{50}$ values.

\section{Statistical analysis}

Data obtained were analyzed using the Statistical Package for Social Sciences (SPSS) Software Version 20.0. The effects of the type of extracts and extract concentrations were evaluated using one way ANOVA and presented as mean \pm standard deviation of 3 replications, followed by Waller-Duncan test for means separation when a significant difference existed at $p<0.05$.

\section{Ethical approval and consents to participate}

All authors hereby declare that "Principles of laboratory animal care" (NIH publication No. 85-23, revised 1985) were followed, as well as specific national laws where applicable. All experiments have been examined and approved by the appropriate ethics committee.

\section{RESULTS}

\section{Extracts yield and phytochemical analysis}

Extract yields and phytochemical constituents were analyzed and the aqueous extract yield was $11.72 \%$ higher than that of ethanolic extract $4.34 \%$. Table 1 shows the result obtained when extracts were tested for the presence of phenolic compounds, alkaloids, flavonoids, polyphenols, tannins, saponin, triterpenes and steroids. The ethanolic extract was found to contain all the phytochemical elements under investigation in the plant, while the aqueous extract showed only a few elements.

\section{In vitro oocysticidal activities of extracts}

Table 2 summarizes in vitro oocysticidal sporulation inhibition of Conyza aegyptiaca extracts against Eimeria tenella. It shows from Table 2 that the plant had significant effects on the sporulation of $E$. tenella oocysts $(p<0.05)$ compared to negative control and the inhibition rate was observed to be concentration dependent. The number of sporulated oocysts decreased with increasing plant treatment concentrations. The highest efficacy after 24 hours of incubation was $98.67 \pm 2.52 \%$ at the concentration of $4 \mathrm{mg} / \mathrm{ml}$ of ethanolic extracts against Eimeria tenella. The lowest efficacy was $5.33 \pm 1.15 \%$ at the concentration of $0.25 \mathrm{mg} / \mathrm{ml}$ after 48 hours of incubation. The Table 2 equally shows the influence of incubation time on the sporulation of Eimeria tenella and it is observed that inhibition rate decreased with an increase in incubation time. The highest efficacy of tested plant extracts was recorded after 24 hours post inoculation which varied according to different concentrations of the tested extracts.

\section{In vitro antioxidant activities of extracts}

\section{Total phenolic and flavonoid content of extracts}

The results of the total phenolic content of Conyza aegyptiaca extracts are presented in Table 3 . This shows that the concentration of phenolic compounds in the ethanolic extract (127.01 mgGAE/g) was significantly higher $(p<0.05)$ than in aqueous extracts $(108.66 \mathrm{mgGAE} / \mathrm{g})$. Also, in the same Table 3, the total flavonoid contents for the various extracts are presented. The ethanol extract had the highest flavonoid content $(14.34 \mathrm{mgCE} / \mathrm{g})$, while the aqueous extract showed the lowest flavonoid content (6.12 $\mathrm{mgCE} / \mathrm{mg}$ ).

\section{Ferric reducing antioxidant power (FRAP) of extracts}

Table 4 presents the results of the reducing power (optical densities) of Conyza aegyptiaca extracts determined by the transformation of $\mathrm{Fe}^{3+}-\mathrm{Fe}^{2+}$. From this Table 4, the ethanolic extracts showed the highest significant reducing power $(0.267 \pm 0.002)$ at the concentration of $200 \mu \mathrm{g} / \mathrm{ml}$. However, there was no significant difference $(p>0.05)$ between the reducing power of standard antioxidant (Vitamin C) and the ethanolic extracts at the concentration of 100 and $200 \mu \mathrm{g} / \mathrm{ml}$. The aqueous extract manifested the lowest reducing power $(0.021 \pm 0.001)$.

\section{Nitric oxide radical scavenging (NO) assay}

The scavenging activity of Conyza aegyptiaca extracts against nitric oxide were recorded with respect to percentage inhibition as presented in Table 5 and showed considerable antioxidant potentials. The ethanolic extracts revealed the highest percentage inhibition $(98.57 \pm 1.25)$ indicating a very good nitric oxide scavenging activity. The aqueous extracts showed the lowest scavenging activity 
Table 1. Phytochemical constituents of extracts.

\begin{tabular}{|c|c|c|c|c|c|c|c|}
\hline \multirow{2}{*}{ Method } & \multicolumn{7}{|c|}{ Extracts phytochemical elements } \\
\hline & alkaloids & polyphenols & flavonoids & tannins & saponin & steroids & triterpenes \\
\hline Aqueous & + & - & + & + & + & - & - \\
\hline Ethanolic & + & + & + & + & + & + & + \\
\hline
\end{tabular}

$+=$ Presence. - = Absence.

Table 2. In vitro Sporulation inhibition percentage of Conyza aegyptiaca extracts on Eimeria tenella.

\begin{tabular}{llcc}
\hline \multirow{2}{*}{ Conc $\mathbf{m g} / \mathbf{m l}$ extracts } & & \multicolumn{2}{c}{ Incubation time } \\
\cline { 2 - 4 } 0.25 & $\mathrm{24h}$ & $\mathbf{4 8 h}$ \\
\cline { 2 - 3 } 0.5 & $\mathrm{EE}$ & $9.33 \pm 2.52^{\mathrm{hA}}$ & $5.00 \pm 1.00^{\mathrm{hA}}$ \\
& $\mathrm{AE}$ & $19.00 \pm 2.65^{\mathrm{gA}}$ & $7.67 \pm 2.08^{\mathrm{hgB}}$ \\
1 & $\mathrm{EE}$ & $39.00 \pm 5.57^{\mathrm{fB}}$ & $13.00 \pm 1.00^{\mathrm{fgC}}$ \\
& $\mathrm{AE}$ & $50.33 \pm 3.51^{\mathrm{eB}}$ & $17.67 \pm 4.93^{\mathrm{fC}}$ \\
2 & $\mathrm{EE}$ & $67.33 \pm 4.73^{\mathrm{dC}}$ & $50.67 \pm 2.08^{\mathrm{eD}}$ \\
& $\mathrm{AE}$ & $80.67 \pm 4.04^{\mathrm{cC}}$ & $54.33 \pm 8.15^{\mathrm{eD}}$ \\
4 & $\mathrm{EE}$ & $83.33 \pm 3.05^{\mathrm{cD}}$ & $66.00 \pm 1.73^{\mathrm{dE}}$ \\
& $\mathrm{AE}$ & $91.00 \pm 1.00^{\mathrm{bD}}$ & $80.33 \pm 4.93^{\mathrm{cE}}$ \\
Negative control & $\mathrm{EE}$ & $86.00 \pm 5.29 \mathrm{~b}^{\mathrm{cE}}$ & $82.33 \pm 3.79^{\mathrm{cE}}$ \\
Positive control & $\mathrm{Tween} 0.3 \%+\mathrm{K}_{2} \mathrm{Cr}_{2} \mathrm{O}_{7}$ & $99.00 \pm 1.00^{\mathrm{aE}}$ & $90.33 \pm 1.53^{\mathrm{bF}}$ \\
& $\mathrm{K}_{2} \mathrm{Cr}_{2} \mathrm{O}_{7}$ & $10.00 \pm 2.65^{\mathrm{hF}}$ & $7.00 \pm 1.00^{\mathrm{hF}}$ \\
& $5 \%$ Phenol & $8.00 \pm 2.00^{\mathrm{hG}}$ & $2.67 \pm 1.16^{\mathrm{hG}}$ \\
\hline
\end{tabular}

$\mathrm{K}_{2} \mathrm{Cr}_{2} \mathrm{O}_{7}$ : Potassium dichromate. The results are the mean $\pm \mathrm{SD}$ of triplicate tests evaluated after 24 and $48 \mathrm{~h}$ of incubation at room temperature. $a, b, c \ldots$. For the same column and $A, B, C$...For the same row, values carrying different superscript letters are significantly different at $p<0.05$.

Table 3. Total phenolic and flavonoid contents of extracts.

\begin{tabular}{lcc}
\hline Extract & Total Phenols (mgGAE/g of extract) & Total Flavonoids (mgCE/g of extract) \\
\hline AE & $108.66 \pm 3,49^{\mathrm{b}}$ & $6.12 \pm 0,02^{\mathrm{a}}$ \\
$\mathrm{EE}$ & $127.01 \pm 3,99^{\mathrm{c}}$ & $14.34 \pm 0,05^{\mathrm{d}}$ \\
\hline
\end{tabular}

GAE: galic acid equivalent, QE: quercetin equivalent. Results in the Table are presented as the Mean \pm SD of triplicate tests. a,b,c.... For the same column and row, values carrying different superscript letters are significantly different at $\mathrm{p}<0.05$.

$(77.04 \pm 1.18)$ and lower values at each concentration compared to the ethanolic extract. The extracts showed a concentration dependent NO scavenging activity that reached $98.57 \%$ at $200 \mu \mathrm{g} / \mathrm{ml}$. However, there was no significant difference $(p>0.05)$, between the standard antioxidant vitamin $\mathrm{C}$, BHT and ethanolic extracts at the concentration of $200 \mu \mathrm{g} / \mathrm{ml}$.

\section{2, 2-Diphenyl-1-picrylhydrazyl (DPPH) radical scavenging assay}

Table 6 shows the radical-scavenging activities and the concentrations which inhibited $50 \%$ of $\mathrm{DPPH}\left(\mathrm{IC}_{50}\right)$ as a function of extracts and concentrations. It follows from this Table 6 that the ethanolic extracts had the highest radical scavenging percentage $(88.53 \pm 3.51)$ at the concentration of $200 \mu \mathrm{g} / \mathrm{ml}$, while the aqueous extracts revealed the lowest scavenging percentage $(31.64 \pm 2.99)$. Compared to the standard antioxidant molecule (Vitamin $\mathrm{C}$ ), the ethanolic extract concentrations exhibited good antioxidant properties. The ethanolic and aqueous extracts presented radical scavenging activities against DPPH free radical in a concentration-dependent manner. Aqueous extracts had highest $\mathrm{IC}_{50}$ value $(48.40 \pm 0.65)$, while the $\mathrm{DPPH}$ radical scavenging potency with a minimum $\mathrm{IC}_{50}$ value (26.10 \pm 1.09$)$ was recorded for ethanolic extracts. Ascorbic acid was used as the standard and the different extracts 
Table 4. Ferric reducing power as a function of extracts and concentration.

\begin{tabular}{lccccc}
\hline \multirow{2}{*}{ Extract } & \multicolumn{5}{c}{ Extract Concentrations/Fractions $(\boldsymbol{\mu g} / \mathbf{m l})$} \\
\cline { 2 - 6 } & $\mathbf{1 2 , 5}$ & $\mathbf{2 5}$ & $\mathbf{5 0}$ & $\mathbf{1 0 0}$ & $\mathbf{2 0 0}$ \\
\hline $\mathrm{AE}$ & $0.021 \pm 0.001^{\mathrm{aA}}$ & $0.053 \pm 0.001^{\mathrm{aB}}$ & $0.094 \pm 0.001^{\mathrm{aC}}$ & $0.150 \pm 0.001^{\mathrm{aD}}$ & $0.167 \pm 0.001^{\mathrm{aD}}$ \\
$\mathrm{EE}$ & $0.076 \pm 0.003^{\mathrm{cC}}$ & $0.126 \pm 0.004^{\mathrm{bD}}$ & $0.180 \pm 0.000^{\mathrm{bD}}$ & $0.224 \pm 0.001^{\mathrm{bE}}$ & $0.267 \pm 0.002^{\mathrm{CE}}$ \\
Vitamin C & $0.064 \pm 0.001^{\mathrm{dB}}$ & $0.131 \pm 0.001^{\mathrm{cD}}$ & $0.195 \pm 0.001^{\mathrm{CD}}$ & $0.247 \pm 0.002^{\mathrm{cE}}$ & $0.298 \pm 0.002^{\mathrm{EE}}$ \\
\hline
\end{tabular}

Values in the table are presented as the Mean \pm SD of triplicate tests. a,b,c.... For the same column and $A, B, C \ldots F o r$ the same row, values carrying different superscript letters are significantly different at $p<0.05$

Table 5. Nitric oxide (NO) radical scavenging activities as a function of extracts and concentration.

\begin{tabular}{lccccc}
\hline \multirow{2}{*}{ Extract } & \multicolumn{5}{c}{ Extract Concentrations/Fractions $(\boldsymbol{\mu g} / \mathbf{m l})$} \\
\cline { 2 - 6 } & $\mathbf{1 2 , 5}$ & $\mathbf{2 5}$ & $\mathbf{5 0}$ & $\mathbf{1 0 0}$ & $\mathbf{2 0 0}$ \\
\hline $\mathrm{AE}$ & $77.04 \pm 1.18^{\mathrm{c}}$ & $83.17 \pm 0.055^{\mathrm{b}}$ & $85.25 \pm 0.027^{\mathrm{b}}$ & $87.84 \pm 0.09^{\mathrm{b}}$ & $89.01 \pm 0.38^{\mathrm{c}}$ \\
EE & $82.91 \pm 0.95^{\mathrm{b}}$ & $84.67 \pm 0.42^{\mathrm{b}}$ & $93.82 \pm 0.36^{\mathrm{a}}$ & $96.55 \pm 0.506^{\mathrm{a}}$ & $98.57 \pm 1.25^{\mathrm{d}}$ \\
Vitamin C & $91.07 \pm 3.627^{\mathrm{a}}$ & $94.95 \pm 1.31^{\mathrm{a}}$ & $96.56 \pm 0.298^{\mathrm{a}}$ & $97.56 \pm 0.95^{\mathrm{a}}$ & $98.55 \pm 2.02^{\mathrm{d}}$ \\
BHT & $94.46 \pm 0.80^{\mathrm{a}}$ & $96.29 \pm 0.11^{\mathrm{a}}$ & $97.27 \pm 0.56^{\mathrm{a}}$ & $97.62 \pm 0.07^{\mathrm{a}}$ & $99.40 \pm 0.05^{\mathrm{d}}$ \\
\hline
\end{tabular}

Values in the table are presented as the Mean \pm SD of triplicate tests. a,b,c.... For the same row and column, values carrying different superscript letters are significantly different at $p<0.05$.

Table 6. DPPH radical-scavenging activities and the concentrations which inhibited $50 \%$ of DPPH (IC 50$)$.

\begin{tabular}{lcccccc}
\hline \multirow{2}{*}{ Extract } & \multicolumn{5}{c}{ Extract Concentrations/fractions $(\boldsymbol{\mu g} / \mathbf{m l})$} \\
\cline { 2 - 7 } & $\mathbf{1 2 , 5}$ & $\mathbf{2 5}$ & $\mathbf{5 0}$ & $\mathbf{1 0 0}$ & $\mathbf{2 0 0}$ & IC $_{\mathbf{5 0}}$ \\
\hline $\mathrm{AE}$ & $31.64 \pm 2.99^{\mathrm{aA}}$ & $43.82 \pm 0.98^{\mathrm{bB}}$ & $47.47 \pm 3.09^{\mathrm{bB}}$ & $56.96 \pm 2.64^{\mathrm{bD}}$ & $61.94 \pm 3.39^{\mathrm{aE}}$ & $48.40 \pm 0.65^{\mathrm{a}}$ \\
$\mathrm{EE}$ & $55.79 \pm 0.12^{\mathrm{CA}}$ & $59.33 \pm 4.11^{\mathrm{dA}}$ & $76.07 \pm 0.31^{\mathrm{eC}}$ & $83.14 \pm 2.78^{\mathrm{fD}}$ & $88.53 \pm 3.51^{\mathrm{eE}}$ & $26.10 \pm 1.09^{\mathrm{b}}$ \\
Vitamin C & $78.99 \pm 1.08^{\mathrm{dA}}$ & $86.14 \pm 0.88^{\mathrm{B}}$ & $88.26 \pm 0.75^{\mathrm{fC}}$ & $89.81 \pm 1.03^{\mathrm{gC}}$ & $93.66 \pm 0.37^{\mathrm{EE}}$ & $19.63 \pm 0.37^{\mathrm{C}}$ \\
\hline
\end{tabular}

Values in the table are presented as the Mean \pm SD of triplicate tests. a,b,c.... For the same column and $A, B, C \ldots$ For the same row, values carrying different superscript letters are significantly different at $p<0.05$.

showed variable antioxidant properties. Lower $\mathrm{IC}_{50}$ value indicates higher radical scavenging activity or higher antioxidant potential.

\section{DISCUSSION}

The current study investigated phytochemical analysis of plant extracts, anti-sporulation of Eimeria tenella oocysts and antioxidant efficacy of Conyza aegyptiaca. Extraction of plant bioactive components depends on multiple factors and the most important of which are the solvent and the extraction method (Savadi et al., 2020). The yield of Conyza aegyptiaca extracts with ethanol and aqueous solvents were 4.34 and $11.72 \%$ extract $/ 100 \mathrm{~g}$ respectively. These results are similar to those observed by Espinoza et al. (2020) who reported higher yields of aqueous extracts than alcoholic extracts of Conyza bonariensis. It has been observed by Savadi et al. (2020) that a high extraction yield for a solvent does not necessarily mean a high content of active ingredients. Ethanolic solvent showed (100\%) qualitative extract yield in terms of bioactive elements compared to aqueous solvent. The analysis in this study agreed with the research of Saleem et al. (2014) who reported that Conyza bonariensis, a cosmopolitan herb is one of the plants generally having all these constituents. Espinoza et al. (2020) supported the fact that alcoholic extracts $(\mathrm{MeOH}$ or EtOH) from plant materials contain a wide variety of polar and nonpolar compounds and that several studies have shown that polar solvents are effective for the extraction of polyphenols. Mohamad et al. (2014) observed that extraction occurred as solvent diffused into plant tissues and solubilized compounds with similar polarity. These authors explained that cell walls have unpolar character and therefore degraded efficiently in organic solvent compared to water, enhancing the extraction process. Furthermore, some plant components are readily soluble in organic solvent compared to water and organic solvents are an option for subsequent extraction in order to maximize the recovery of phenolic compounds. The identification of bioactive elements in this study has been supported by the research of Al-Rifai et al. 
(2017) who reported similar elements in ethanolic extracts. Thus, the extracts of Conyza aegyptiaca had high quality yield when extracted with $96 \%$ ethanol. The difference in the extraction yields of ethanol and aqueous solvents may be attributed to differences in polarity of compounds found in plants and such differences have been reported by Mohamed et al. (2012).

Anticoccidial properties are mostly assessed through oocysts sporulation inhibition. To the best of our knowledge, this is the first study to evaluate the effects of Conyza aegyptiaca as inhibitors of Eimeria tenella oocysts sporulation in vitro. The efficacy of ethanolic extracts were significantly higher $(p<0.05)$ in a concentration depended manner compared to aqueous extracts. Wabo Poné et al. (2011) reported similar findings and proposed that the concentration dependent activity of extracts could result from the increased amount of bioactive compounds. This was consistent with the results of Arlette et al. (2019) who demonstrated that ethanolic extracts of both Ageratum conyzoides and Vernonia amygdalina had higher anticoccidial activity than aqueous extracts on E. tenella in vitro and this anti-sporulation activity could be attributed to a variety of secondary metabolites present. Several studies in vitro and in vivo have reported the inhibitory effect of plant extracts containing phenolic compounds and that natural polyphenolic component derived from medicinal plants inhibited cell invasion of $E$. tenella sporozoites in vitro (Arlette et al., 2019). These researchers further reported that extracts containing polyphenolic compounds may have the ability to inhibit enzymes responsible for the sporulation process of the coccidian oocysts. Mannitol (energy source of oocyst) is necessary during sporulation process of oocysts of $E$. tenella in the presence of mannitol-1 phosphate dehydrogenase, mannitol-1 phosphatase, mannitol dehydrogenase and hexokinase enzymes (Yamssi et al., 2017). It can therefore be suggested that, extract components of Conyza aegyptiaca exhibited antisporulation effect by interfering in the physiological processes necessary for sporulation thus inhibiting or inactivating the enzymes responsible for the sporulation process.

In normal and healthy body conditions, there is a balance between reactive oxygen species formation or free radical and endogenous antioxidant defense mechanisms (Arulselvan et al., 2016). According to Lobo et al. (2010) antioxidants are considered stable molecules that are able to donate an electron to a free radical, thereby scavenging the free radical and stopping it from causing further damage. Several methods are commonly used to measure the antioxidant capacity of extracts. Each method results in the generation of or uses a different radical that is directly involved in the oxidative process through a variety of mechanisms. No single assay can represent the total antioxidant capacity, since different methods can yield widely diverging results. Based on different mechanisms, total phenol and flavonioid contents, ferric reducing antioxidant power, nitric oxide scavenging and DPPH radical scavenging assays were used to determine the in vitro antioxidant properties of Conyza aegyptiaca.

The amount of total phenolic compounds varied in the different Conyza aegyptiaca extracts, ranging from 108.66 mgGAE g-1 aqueous extract to $127.01 \mathrm{mgGAE}$ g-1 ethanolic extract. These results were similar to the findings of Ivanovic et al. (2020), who reported high content of total phenols, flavonoids, and significant antioxidant activity in ethanolic extracts owing to their higher polarity and good solubility. As antioxidants, phenolic compounds are known to terminate oxidation by participating in the reactions through resonance stabilized free radical forms, act as free radical scavengers, as well as chelating trace metals involved in free radical production (Zeb, 2020). Research suggests that hydrogen donation may be a key mechanism of action for the antioxidant activity of phenolic compounds (Riyadh et al., 2014). Polyphenols are able to act as reducing agents, singlet oxygen quenchers and peroxide decomposition (Kopustinskiene et al., 2020). The total flavonoids present powerful antioxidant activities by acting as a hydrogen donor to receive free radicals thus generating stable intramolecular hydrogen bonds with semi-quinoid free radicals which block the free-radical chain reaction (Chen et al., 2020). The high ferric reducing antioxidant power $(0.267 \pm 0.002)$, Nitric Oxide (98.57 \pm 1.25$)$ and DPPH (88.53 \pm 3.51$)$, radical scavenging assays of ethanolic extract of Conyza aegyptiaca compared to vitamin $C$ at the concentration of $200 \mu \mathrm{g} / \mathrm{ml}$ may be linked to its high phenolic contents of $127.01 \pm 3.99 \mathrm{mgGAE} / \mathrm{g}$. These results suggest that phenolic compounds contributed significantly to antioxidant activity of Conyza aegyptiaca. Baroni et al. (2018) and Phuyal et al. (2020) reported such positive correlation between phenolic contents and antioxidant activity and further explained that the phenolic contents of any plant are directly related to their antioxidant properties. Ouerghemmi et al. (2017) observed significant positive correlations between total phenolic content and values for total antioxidant activity of leaves and flowers of two Ruta origins and that total phenolics were highly correlated with the reducing power in the spontaneous flowers and cultivated flowers, indicating the significant contribution of phenolics to these antioxidant assays. This is also consistent with the findings of Katırcı et al. (2020) who reported a superior quality in terms of total phenol contents (TPC), total flavonoid contents (TFC) and antioxidant values in commercial tomato pastes. The results obtained from this study indicated that extracts contain powerful antioxidants, all of which are believed to ameliorate oxidative stress and play a role in reducing the risk of degenerative diseases.

It has been reported in literature that some antioxidants act as reducing agents, capable of deactivating oxidants or free radicals into their stable forms (Phuyal et al., 2020). The reducing capacity of compounds from $\mathrm{Fe} 3+$ /ferricyanide complex to Fe2+/ferrous form may serve as a significant indicator of its potential antioxidant activity. Phenolic compounds are important plant constituents with 
redox properties responsible for antioxidant activity, because the hydroxyl groups in them are responsible for facilitating free radical scavenging through reduction reactions (Ghasemzadeh and Ghasemzadeh, 2011; Zeb, 2020). Gallic acid is a phenolic acid containing three hydroxyls and one carboxylic acid group, and the hydroxyl group is responsible for antioxidant function by forming gallic acid-free radical (Chen et al., 2020). In this study, the greatest ferric reducing antioxidant power (FRAP) was recorded with ethanolic extracts and this was similar to that of Fidrianny et al. (2018) who reported a positive correlation between FRAP of ethanolic extracts of Morinda citrifolia, suggesting that the extract may contain several compounds with redox potentials. Phuyal et al. (2020) explained earlier that the phenolic content of any plant is directly related to their antioxidant properties. Therefore, the high antioxidant reducing power of ethanolic extracts of Conyza aegyptiaca compared to the standard vitamin $C$ is linked to its high phenolic content.

Ghasemzadeh and Ghasemzadeh (2011) reported that scavenging radical species such as nitrogen species (NO), suppressing NO formation by inhibiting some enzymes or chelating trace metals involved in free radical production, up regulating or protecting antioxidant defense mechanisms mediate antioxidant properties of phenolic and flavonoid compounds. The antioxidant ability of Conyza aegyptiaca was generally high in both ethanolic and aqueous extracts at all concentrations, but the NO scavenging activity of ethanolic extract was significantly $(p<0.05)$ much higher $(98.57 \pm 1.25)$ than in aqueous extract $(89.01 \pm 0.38)$ at the concentration of $200 \mu \mathrm{g} / \mathrm{ml}$. Nitric oxide radical scavenging activity is also correlated to the presence of phenolic compounds (Priya et al., 2017). These findings suggest from this study that the high NO scavenging activity is linked to the high phenolic contents observed in Conyza aegyptiaca.

DPPH radical is considered to be a model of a stable lipophilic radical (Mohamed et al., 2012). The stable DPPH radical model is a simple, acceptable and most widely used technique to evaluate the radical scavenging potency of plant extracts (Shivani and Anjali, 2018). DPPH is a stable organic free radical, which loses its absorption spectrum band at 515-528 nm when it accepts an electron or hydrogen radical to become a stable molecule. The ethanolic extract of Conyza aegyptiaca showed a significant higher $(p<0.05)$ DPPH free radical scavenging activity at the concentration of $200 \mathrm{mg} / \mathrm{ml}$ and results supported by the findings of Singh et al. (2019) who showed higher ethanolic extract scavenging activity of Phyllanthus niruri than aqueous extract. Riyadh et al. (2014) reported that the effect of antioxidants on DPPH radical has been suggested to be due to their hydrogen donating ability, which leads to the reduction of DPPH in ethanol solution to the formation of a diamagnetic or non-radical form DPPHH. Aryal et al. (2019) also suggested that plant antioxidants have ideal structural characteristics for DPPH free radical scavenging. Thus, the DPPH free radical scavenging assay suggest that extracts components involved are capable of scavenging free radicals through electron or hydrogen donating mechanisms and might be able to prevent the initiation of deleterious free radical mediated chain reactions in susceptible matrices.

\section{Conclusion}

Extracts showed varying degrees of anticoccidial and antioxidant activities in different assays. In general, ethanolic extracts were the most active and provided the scientific basis for phytchemical analysis, anticoccidial and antioxidant activity in broiler microflora. Therefore, data from this study could be used for developing bioactive elements for natural anticoccidials and antioxidants of health promoting activities and in pharmaceutical industries. However, further studies should be explored to better understand the mechanisms of action and to evaluate the toxicity of Conyza aegyptiaca.

\section{COMPETING INTEREST}

The authors declared that they have no competing interest.

\section{ACKNOWLEDGEMENTS}

Authors wish to extend their sincere gratitude to Dr. Isa Danladi Jatau and Professor O. O. Okubanjo, Department of Veterinary Parasitology and Entomology, Faculty of Veterinary Medicine, Ahmadu Bello University, Zaria, Nigeria, for providing Eimeria tenella sporulated oocysts, directives and methods of parasite propagation. The effort of the villagers who locally highlighted the medicinal importance of the plant is also appreciated.

\section{REFERENCES}

Abbas, A., Iqbal, Z., Abbas, R. Z., Khan, M. K., \& Khan, J. A. (2015). In-vitro anticoccidial potential of Saccharum officinarum extract against Eimeria oocysts. Boletin latinoamericano y del caribe de plantas medicinales y aromaticas, 14(6), 456-461.

Abdul, R., \& Muhammed, S. (2016). Assessment of the level of protection against coccidiosis in broiler breeders conferred by a live anticoccidial vaccine, and its Influence on early growth and development. Theses and Dissertations, Department of Veterinary Sciences \& Animal Husbandry, University of Arkansas, p. 1654.

Adnane, R., Sanaa, A., Latifa, B., Fouzia, C., \& Najat, C. (2013). Oocysticidal effect of essential oil components against chicken Eimeria oocysts. International Journal of Veterinary Medicine, Volume 2013, Article ID 599816, 8 pages.

Adulugba, I. A., Goselle, O. N., Ajayi, O. O., \& Tanko, J. T. (2017). Development of a Potent Anti-coccidial Drug: A Phyto-Synthetic Approach. American Journal of Phytomedicine and Clinical Therapeutics, 5(1), 1-7.

Akakpo, H. B., Akpovi, D. C., Medehouenou, M. C., Assogba, M. F., Dansou, H. P., \& Gbénou, D. J. (2016). Conyza aegyptiaca (L.) Dryand ex. Aiton extracts exhibit antioxidant activity and 
prevents hepatic glucose liberation in vitro. International Journal of Biosciences, 9(6), 431-439.

Al-Gawad, A. A., Mahdy, O. A., El-Massry, A. A., \& Al-Aziz, M. S. (2012). Studies on coccidia of Egyptian Balady breed chickens. Life Science Journal, 9(3), 568-576.

Al-Rifai, A., Aqel, A., Al-Warhi, T., Wabaidur, S. M., Al-Othman, Z. A., \& Badjah-Hadj-Ahmed, A. Y. (2017). Antibacterial, antioxidant activity of ethanolic plant extracts of some Convolvulus species and their DART-ToF-MS profiling. Evidence-Based Complementary and Alternative Medicine, Volume 2017, Article ID 5694305, 9 pages.

Arlette, T. N; Nadia, C. A. N; Yondo Jeanette, Y; Gertrude, T. M; Stephanie, T. M., Wabo Pone, J., \& Mpoame, M. (2019). The in vitro anticoccidial activity of aqueous and ethanolic extracts of Ageratum conyzoides and Vernonia amygdalina (Asteraceae). World Journal of Pharmacy and Pharmaceutical Sciences, 8(3), 38-49.

Arulselvan, P., Fard, M. T., Tan, W. S., Gothai, S., Fakurazi, S., Norhaizan, M. E., \& Kumar, S. S. (2016). Role of antioxidants and natural products in inflammation. Oxidative Medicine and Cellular Longevity, Volume 2016, Article ID 5276130, 15 pages.

Aryal, S., Baniya, M. K., Danekhu, K., Kunwar, P., Gurung, R., \& Koirala, N. (2019). Total phenolic content, flavonoid content and antioxidant potential of wild vegetables from Western Nepal. Plants, 8(4), 96.

Baroni, V. M., Gastaminza, J.,Podio, S. N., Lingua, S. M., Wunderlin, A. D., Rovasio, L. J., Dotti, R., Rosso, C. J., Ghione, S., \& Ribotta, D. P. (2018). Changes in the antioxidant properties of quince fruit (Cydonia oblonga Miller) during jam production at industrial scale. Journal of Food Quality, Volume 2018, Article ID 1460758, 9 pages.

Builders, M., Wannang, N., \& Aguiyi, J. (2011). Antiplasmodial activities of Parkia biglobosa: In vivo and in vitro studies. Annals of Biological Research, 2(4), 8-20.

Castañeda, Q. E. R., \& González, D. E., (2015). Control of Avian Coccidiosis: Future and present natural alternatives. Bio Med Research International, Volume 2015 |Article ID 430610, 11 pages.

Chanda, S., \& Dave, R. (2009). In vitro models for antioxidant activity evaluation and some medicinal plants possessing antioxidant properties: An overview. African Journal of Microbiology Research, 3(13), 981-996.

Chen, S., Li, X., Liu, X., Wang, N., An, Q., Ye, X. M., Zhao, Z. T., Zhao, M., Han, Y., Ouyang, K. H., \& Wang, W. J. (2020). Investigation of chemical composition, antioxidant activity, and the effects of Alfalfa flavonoids on growth performance. Oxidative Medicine and Cellular Longevity, Volume 2020, Article ID 8569237, 11 pages.

El-Ashram, A. S, Aboelhadid, S. M., Gadelhaq, S. M., Arafa, W. M., Abdel-Razik, A. R. H., Abohamra, S., \& Abdelaziz, K. T. (2019). Oral inoculation of ultraviolet-irradiated Eimeria species oocysts protects chickens against coccidiosis. Parasitology Research, 118(11), 3173-3183.

Espinoza, R. V., Peñarreta, J., Quijano-Avilés, M., Lucas, A. B., Chóez-Guaranda, I., \& Santana, P. M. (2020). Antioxidant activity and GC-MS profile of Conyza bonariensis L. leaves extract and fractions. Revista Facultad Nacional de Agronomía Medellín, 73(3), 9305-9313.

Fatoba, A. J., \& Adeleke, M. A. (2018). Diagnosis and control of chicken coccidiosis: a recent update. Journal of Parasitic Diseases, 42(4), 483-493.

Fidrianny, I., Octaviani, G. D., \& Kusmardiyani, S. (2018). Study of Antioxidant Profile and Phytochemical Content of Different Organs Extracts of Morinda citrifolia L. Journal of Pharmaceu- tical Sciences and Research, 10(8), 2102-2105.

Firouzi, S., Mosleh, N., Tohidi, S. S., Taebipur, M. J., \& Farjani, K. G. (2014). Efficacy of anticoccidial vaccination of chickens via different routes: A comparative study. Journal of Veterinary Medicine, 17(4), 293-301.

Frölich, S., Farhat, J., \& Wallach, M. (2013). Designing strategies for the control of coccidiosis in chickens on poultry farms using modern diagnostic tools. Reports in Parasitology, 3, 1-10.

Ghasemzadeh, A., \& Ghasemzadeh, N. (2011). Flavonoids and phenolic acids: Role and biochemical activity in plants and human. Journal of Medicinal Plants Research, 5(31), 66976703.

Hady, M. M., \& Zaki, M. M. (2012). Efficacy of some herbal feed additives on performance and control of cecal coccidiosis in broilers. APCBEE Procedia, 4, 163-168.

Ivanović, S., Avramović, N., Dojčinović, B., Trifunović, S., Novaković, M., Tešević, V., \& Mandić, B. (2020). Chemical composition, total phenols and flavonoids contents and antioxidant activity as nutritive potential of roasted hazelnut skins (Corylus avellana L.). Foods, 9(4), 430-439.

Kant, V., Singh, P., Verma, P. K., Bias, I., Paemar, M. S., Gopal, A., \& Gupta, V. (2013). Anticoccidial drugs used in poultry: An overview. Science International, 1(7), 261-265.

Katırcı, N., Işık, N., Güpür, Ç., Guler, H. O., Gursoy, O., \& Yilmaz, Y. (2020). Differences in antioxidant activity, total phenolic and flavonoid contents of commercial and homemade tomato pastes. Journal of the Saudi Society of Agricultural Sciences, 19(4), 249-254.

Kopustinskiene, D. M., Jakstas, V., Savickas, A., \& Bernatoniene, J. (2020). Flavonoids as anticancer agents. Nutrients, 12(2), 457.

Kpegba, K., Agbonon, A., Amouzou, E., \& Gbeassor, M. (2011). Effect of Conyza aegyptiaca on the frog semi-isolated heart. Journal of Applied Pharmaceutical Science, 1(7), 36-39.

Lobo, V., Patil A., Phatak, A., \& Chandra, N. (2010). Free radicals, antioxidants, and functional foods: impact on human health. Pharmacognosy Review, 4(8), 118-126.

Mahmoud, A. A., Al-Shihry, S. S., \& Hegazy, M. E. F. (2009). Biological activity of a phloroglucinol glucoside derivative from Conyza aegyptiaca. Zeitschrift für Naturforschung C, 64(7-8), 513-517.

Mohamad, N. A. N., Arham, N. A., Jai, J., \& Hadi, A. (2014). Plant extract as reducing agent in synthesis of metallic nanoparticles: a review. In Advanced Materials Research (Vol. 832, pp. 350355). Trans Tech Publications Ltd.

Mohamed, F., El-Maati, M. F. A., Labib, S. M., Al-Gaby, A. M. A., \& Ramadan, M. F. (2012). Antioxidant properties of different extracts from five medicinal plants. Zagazig Journal of Agricultural Research, 39(4), 1-13.

Noghogne, L. R., Gatsing, D., Kodjio, N., Sokoudjou, J. B., \& Kuiate, J. R. (2015). In vitro antisalmonellal and antioxidant properties of Mangifera indica L. stem bark crude extracts and fractions. Journal of Pharmaceutical Research International, 5(1), 29-41.

Ouerghemmi, I., Rebey, I. B., Rahali, F. Z., Bourgou, S., Pistelli, L., Ksouri, R., ... \& Tounsi, M. S. (2017). Antioxidant and antimicrobial phenolic compounds from extracts of cultivated and wild-grown Tunisian Ruta chalepensis. Journal of food and drug analysis, 25(2), 350-359.

Phuyal, N., Jha, P. K., Raturi, P. P., \& Rajbhandary, S. (2020). Total phenolic, flavonoid contents, and antioxidant activities of fruit, seed, and bark extracts of Zanthoxylum armatum DC. The Scientific World Journal, Volume 2020, Article ID 8780704, 7 pages. 
Priya, H. S., Prakasan, N., \& Purushothaman, J. (2017). Antioxidant activity, phenolic flavonoid content and high performance liquid chromatography profiling of three different variants of Syzygium cumini seeds: A comparative study. Journal of Intercultural Ethnopharmacology, 6(1), 107-114.

Riyadh, A. S. T., Xiang, R. C., Nabil, A. H., Rahman, T. R., Guo, W. L. (2014). Antioxidant and Conyza bonariensis: A Review. European Academic Research, 2(6), 2286- 4822.

Saleem, M., Naseer, F., Ahmad, S., Nazish, A., Bukhari, R. F., Rehman, U. A., Khan, M. I., Sadiq, S., \& Javed, F. (2014). Hepatoprotective activity of ethanol extract of Conyza bonariensis against paracetamol induced hepatotoxicity in Swiss Albino mice. American Journal of Medical and Biological Research, 2(6), 124-127.

Savadi, S., Vazifedoost, M., Didar, Z., Nematshahi, M. M., \& Jahed, E. (2020). Phytochemical analysis and antimicrobial/ antioxidant activity of Cynodon dactylon (L.) Pers. rhizome methanolic extract. Journal of Food Quality, Volume 2020, Article ID 5946541, 10 pages.

Shivani, D., \& Anjali, S. (2018). Antioxidant activity and improvement in the yield of antioxidant compounds. Asian Pacific Journal of Health Sciences, 5(2), 86-91.

Singh, P. R., Pal, A., \& Pal, K. (2019). Antioxidant activity of ethanolic and aqueous extract of Phyllanthus niruri In vitro. World Journal of Pharmacy and Pharmaceutical Sciences, 5(6), 1994-2000.
Sundar, B. S., Harikrishnan, J. T., Latha, R. B., Chandra, S. G., \& Kumar, S. (2017). Anticoccidial drug resistance in chicken coccidiosis and promising solutions: A review. Journal of Entomology and Zoology Studies, 5(4), 1526-1529.

Wabo Poné, J., Fossi Tankoua, O., Yondo, J., Komtangi, M. C., Mbida, M., \& Bilong Bilong, C. F. (2011). The in vitro effects of aqueous and ethanolic extracts of the leaves of Ageratum conyzoides (Asteraceae) on three life cycle stages of the parasitic nematode Heligmosomoides bakeri (Nematoda: Heligmosomatidae). Veterinary medicine international, Volume 2011, Article ID 140293, 5 pages.

Yamssi, C., Payne, V. K., Nadia, C. A. N., Kodjio, N., Etung, K., Megwi, L., Kuiate, R. J., \& Mpoame M. (2017). In vitro anticoccidial, antioxidant activities and cytotoxicity of Psidium guajava extracts, Journal of Parasitic Diseases: Diagnosis and Therapy, 2(2), 14-24.

Zeb, A. (2020). Concept, mechanism, and applications of phenolic antioxidants in foods. Journal of Food Biochemistry, 44(9), e13394.

Zou, Y., Zhao, Y., \& Hu, W. (2015). Chemical composition and radical scavenging activity of melanin from Auricularia auricula fruiting bodies. Food Science and Technology, 35(2), 253-258. 